\title{
INTERREGIONAL FILTERING-DOWN OF A HOUSEHOLD ASSET: THE CASE OF AUTOMOBILE AGE MIX IN ISRAEL
}

\author{
Eliahu Stern*
}

\section{Abstract}

An interregional filtering-down process of a household asset was examined through the study of spatial changes in the age mix of private cars. The relative share effect of shift share analysis was used to identify cities exporting and importing old cars using Israel as a national case. A causal path model supported the hypothesis that a core-periphery filtering-down process characterizes the spread of private cars. A further analysis of the car market demonstrated the regional impact of the automobile filtering process. The latter was found to have a core-positive effect that both directly and indirectly, increases regional inequality. Peripheries thus are always expected to have a relatively larger share of secondary goods than do the cores.

Thompson (1968) recognized a systematic spatial trend along the industrial innovative cycle and proposed a filtering-down process of industry from core innovating areas to less industrially sophisticated peripheries. This process usually is associated with studies in the realm of core-periphery, with regard to understanding sources of disparities, and with the paradigm of diffusion in an attempt to understand their mechanisms. The contribution of Thompson related mainly to the understanding of coreperiphery disparities. This study was intended to enhance the understanding of the sources of these disparities by highlighting regional chains of exchange of what is considered to be one of the most valuable household assets - the private car. The study also was intended to contribute another aspect to the issue of spatial disparities through the filtering-down of this asset.

The theoretical context of the study is presented first and followed by a proposed mechanism by which the age structure (hereafter the age mix) of the car market is changed. Using Israel as a national case, both a shift-share and a path analysis are used to examine and test the filtering-down process. Finally, the regional implications of the process are discussed.

\footnotetext{
*Associate Professor of Geography and Transportation Planning, Ben-Gurion University of the Negev, Beer Sheva, Israel. The author wishes to thank Shaul Krakover and the reviewers for their cirtiques and comments.
}

\section{Theoretical Considerations and Hypothesis}

Core and periphery areas long have been recognized as standing in an asymmetrical relationship of dominance and dependency. This relationship is articulated through four major processes - decision making and control, capital flows, innovative diffusion, and migration (e.g. Friedmann, 1973; Williams, 1977). An important measure of inequality in a core-periphery context is the standard of living (e.g. Smith, 1979). When this standard is allied to the spread, or the exchange, of capital assets or goods, the above mentioned process of capital flows becomes a relevant interpretative framework.

Capital flows from core to periphery are countered, in general, by spread or trickle-down effects that are expected to reduce regional disparities (e.g. Berry, 1972). There is evidence, however, that backwash, or polarization effects, have far outweighed the trickle-down effects, thus increasing regional disparities (e.g. Brown, 1981; Gaile, 1979). This usually is the case when spread-backwash forces are expressed and measured in terms of pure capital flows, but is not necessarily the case when other measures of flow or exchange are considered. In the latter case, regional disparities may be widened, even without the backwash forces. As Thompson (1968) showed, the filtering-down of industry did not affect the regional disparity because the periphery continued to absorb industries less sophisticated than those in the core. If a filtering-down process also characterizes the spread of household assets, a situation of stable, or even enlarged, regional disparity also may exist for these assets, thus adding another dimension to regional inequality in living standards.

Filtering processes, both upwards and downwards, have been studied mainly in relation to the housing market (e.g. Kirkland, 1969; Grigsby, 1963; Leven et al., 1976; Boddy and Gray, 1979). In the housing case the population is the mobile element in the process and both its characteristics and the past occupancy of the housing determine whether the filtering is up or down. Unlike the housing case, if filtering characterizes the spread of a household asset, it is the asset rather than the population that is the mobile element in the process.

With this in mind, reference is made to the private car, the asset selected for this study. It should be stressed that the focus is not on a diffusion process of cars, but rather 
on their interregional exchange through the spatial differentials in their age mix. If the cars are divided into old, medium, and new age categories, the relative weights of the categories at any given place are likely to change over time due to the mechanism shown diagrammatically in Figure 1. The mechanism is comprised of four elements. Scrapping due to road accidents subtracts cars from all age categories, whereas retirement subtracts cars only from the old age category. The age mix also changes each year as cars considered new or medium age in the previous year change age status and become medium or old age, respectively. Finally, the fourth and most important element of this mechanism are inter-nodal transactions that are affected by local demands. These transactions refer to any purchases of used cars in out-of-town markets that involve changes in the place of registration. The filtering down of cars, in a general context, refers to the transition of ownership of a car from a person, or persons, of a high socioeconomic status to a person, or persons, of a lower status. In a core-periphery context, the filtering-down of cars refers to the transfer of ownership of a car from a resident, or residents, of a core area to a resident, or residents, of a peripheral area. This transfer depends on the demand and supply of cars of all age categories in both areas and thus it also could involve, although less likely, a filtering-up process indicated by the two-way arrows in Figure 1. Demand, in general, is related closely to such socioeconomic characteristics as income, age, education and occupation (Hocherman, et al., 1984; Manski and Sherman, 1980; Lave and Train, 1979) and therefore it would vary at different places. Demand also has been found to vary with vehicle cost and model (Hocherman, et al., 1987), with marketing efforts (Lave and Bradley, 1980), with lifecycle stages (Hopkin 1983; Carpenter, et al., 1980), with road network development and quality (Riddel, 1970; Lansing and Hendricks, 1967), and with population density (Tanner, 1977). All these factors relate to characteristics of the potential consumers, their local environment and, to some extent, to the characteristics of the vehicle. Recent studies using discrete choice models pay more attention to the latter (e.g. Hensher, 1988; Hensher and Le Plastrier, 1985), including, for example, fuel efficiency, but none of the studies refers to the structure and location of the market, factors that are more relevant to the context of the present study. The socio-economic characteristics of the potential consumers and the factors relating to their local environment lead to the assumption that peripheral areas are characterized both by a relatively low demand and a low internal supply of cars. The low internal supply is the result mainly of the low rejuvenation rate of the private car fleet in the periphery. Based on the assumption that the car is no longer a symbol of social esteem in either the core or the periphery, but rather is a necessary tool for keeping the economy going, a similar latent demand curve in the periphery (despite its general lower income, e.g. Shachar and Lipshitz (1981)), and a smaller supply, used-car shoppers residing in small market areas will pay more for a given car. This difference in price consequently may encourage purchasing in external larger markets. To that end, studies have shown that a large proportion of the low price car buyers are shoppers who are will to travel for small differences in car price (Pashingian, 1961). By travelling to central markets, these consumers also are able to obtain larger numbers of quotations, car models and makes.

The supply of used cars already has been found to be closely associated with central place status and nodality in transportation terms (Gordon, 1985; Meir, 1981; Ajo, 1955). Central place status is based, among other things, on local consumption opportunities that simply reflect the local potential supply. The smaller the local supply, the larger is the outflow of local consumers (Cohen, 1976). To the extent that inter-nodal transactions are based on local supplies and demands, a geographic segmentation may exist in the map of the car age mix. Therefore a large proportion of cars previously registered in core areas would be expected in peripheral areas. Accordingly, the major hypothesis of this study is that a core-periphery filtering-down characterizes the spread of private cars. The following sections test this hypothesis.

\section{Operational Definitions and Data}

Ideally, the analysis of inter-nodal car ownership transactions would require longitudinal information of actual transactions on an origin-destination basis. Since such data are not available, an indirect approach based on nodal-aggregated longitudinal changes in the age of private cars was used. A crucial factor in this approach is whether a change of the age definition would affect the age mix over time. In other words, would a change in the definition of a certain age category only raise (lower) the longitudinal distribution of the relative weight of the category as a whole, or would it also change the distribution itself.

Using data on the number of private cars of different ages registered in Israel (Central Bureau of Statistics, 1967-1983), four curves showing changes in the relative weight of new cars between 1969 and 1983 were constructed, with the curves reflecting different new car definitions ranging from one year to four years, respectively (Figure 2). A cursory examination of Figure 2 reveals a high degree of similarity of the curves. Starting with one year as a definition for new cars, and increase in the time 


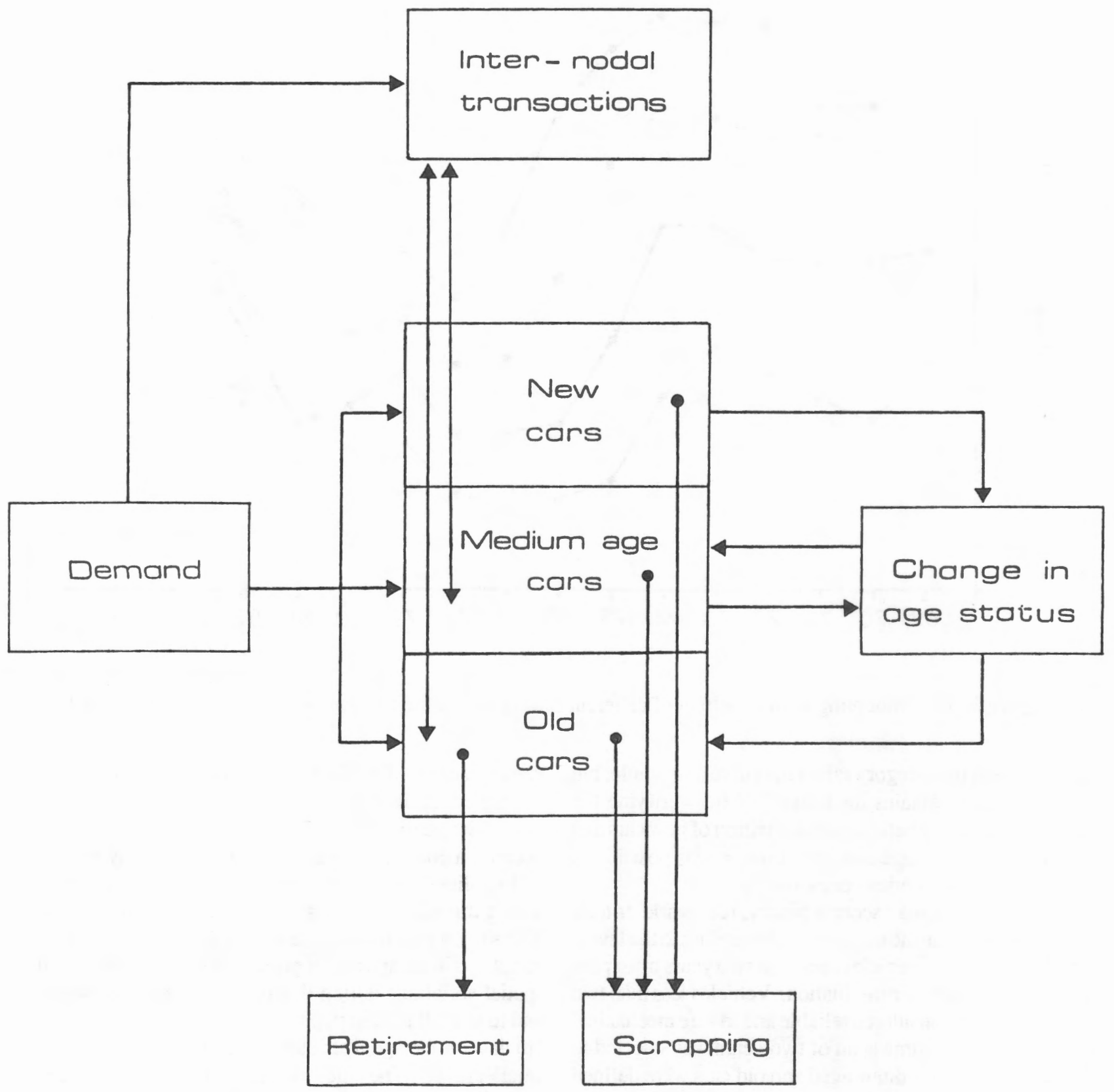

Figure 1. The Mechanism for Change in the Automobile Age Mix 


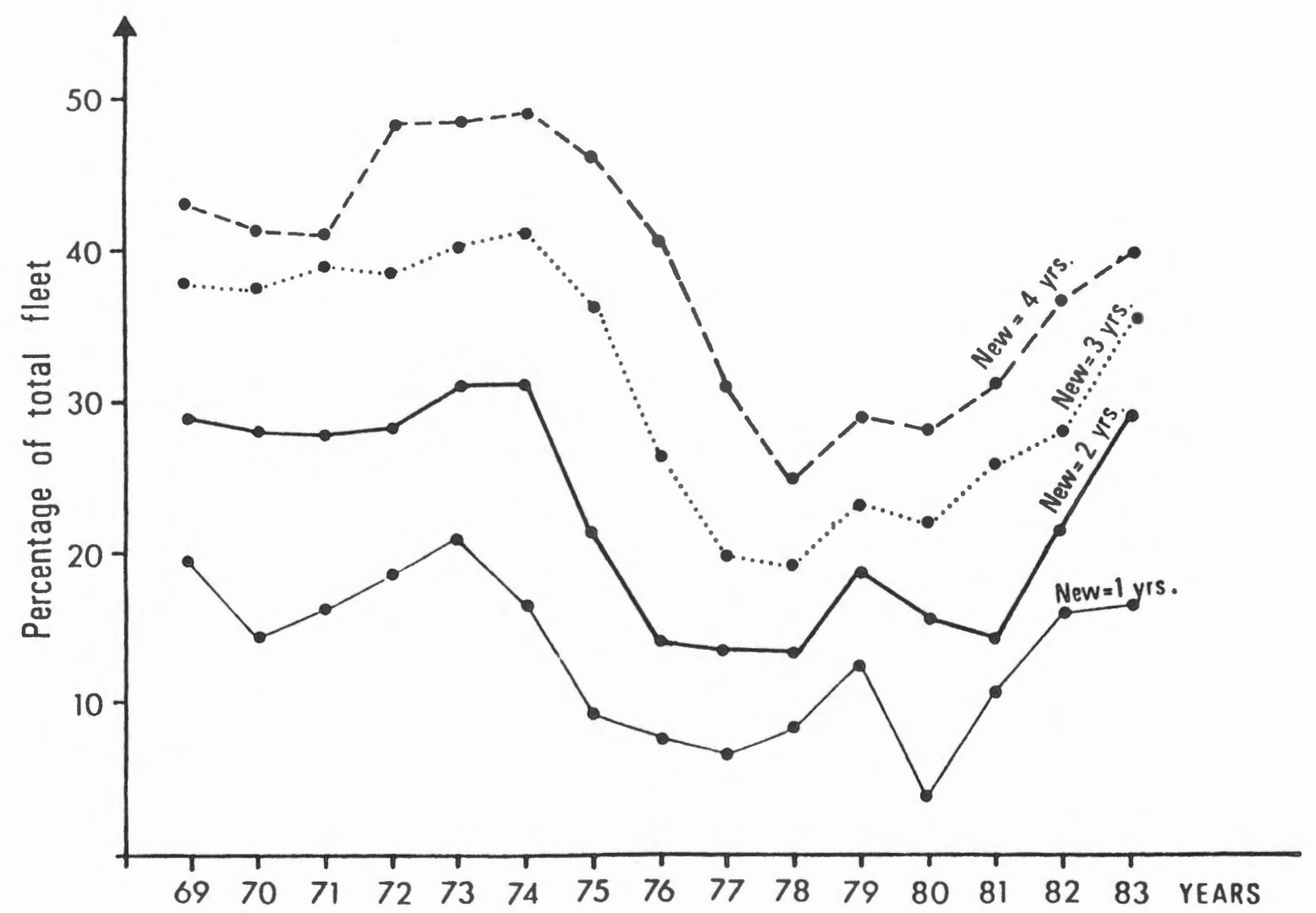

Figure 3. Experimenting with the effect of different time spans on the relative weight of new cars in Israel.

span defining the category raises the curve as a whole, but the distribution remains unchanged. After verifying the lack of dependency between the definition of new cars and the behavior of the age mix over time, it was possible to define the age categories operationally.

Although it may seem arbitrary, real world criteria were used to define the categories. According to the law in Israel, every motor vehicle older than two years must pass an annual road safety examination. Vehicles less than two years of age are considered reliable and in safe mechanical condition. Thus a time span of two years was selected to define new cars. Medium-aged and old cars were defined on the basis of the cumulative mileage driven, and consequently price. A sharp decreases in the price of used cars is noticed when the car approaches 60,000 miles. With an average annual mileage of 9,000 miles per private car in Israel (Central Bureau of Statistics, 1983), this point is reached after approximately seven years of continuous use. Cars between two and seven years of age therefore were categorized as of medium age and cars older than seven years were defined as old.

The years 1981 to 1983 were chosen for the study because a consistent shift across all cities away from old and medium aged cars toward new ones was evidenced during this period due to a tax reduction on imported cars. The shift was, however, differential, resulting in spatial variations in the age mix of private cars. The analysis of the spatial variations during this period is based on 34 cities and towns, all having populations of over 20,000 in 1981. No data on the age distribution of cars were available for smaller towns. The cities were categorized into three coreperiphery type regions on the basis of their location.

\section{Exporters and Importers of Used Cars}

The division of the private car market into three age categories permits examination of different types of change in different cities; a first step in an indirect approach to 
testing the filtering-down hypothesis. The relative share effect of a shift share analysis can provide insight into these comparative changes. This effect concentrates on changes in the number of cars in a given age category in a given city that are attributable to the net shift of this category into or out of the city relative to shifts in all other cities in the country. Since concern is with a mobile asset, the proportion of the total change due to the relative share effect can be attributed to inter-nodal transactions of car ownership. The analysis can indicate further how each city shared in the total increase of private cars - whether a city was an exporter or an importer of cars of a given age category.

The mathematical formulation of the relative share effect (RSE) for each age category i in each city is:

$$
\operatorname{RSE}_{i}=\left\{\left[\left(R_{i}^{*}-R_{i}\right) / R_{i}\right]-\left[\left(B_{i}^{*}-B_{i}\right) / B_{i}\right]\right\} R_{i}
$$

where $B$ is the number of cars in age category $i$ in the whole country, $B_{i}$ and $B_{i}{ }^{*}$ are the beginning-of-period and end-ofperiod, respectively. Similarly, $R_{i}$ and $R_{i}^{*}$ are the beginning-of-period and end-of-period values, respectively, cars of cars of age category i in each city. For purposes of comparison, the RSE is expressed in percentage, indicating the proportion of the total change in each age category (positive or negative) and city attributable to inter-nodal transfers of car ownership.

As a descriptive tool for inter-nodal transactions, the relative share effect is relevant only to the used cars segment of the market. Since new cars are bought directly from the manufacturers, the shift share effect calculated for them reflects only changes in their local demand. The used car market is defined to contain only medium-aged cars and old cars. However, due to the relatively high cost of cars in Israel (including a 200 percent import tax, a 40 percent forced governmental bond, and a 15 percent value added tax) many new car buyers keep their new cars for long periods (Hocherman and Prashker, 1983). Internodal ownership transactions therefore are assumed to involve only a small part of the medium-aged car population. This assumption is supported by the calculated values of the relative share effect of medium-aged cars. Changes in the individual city shares of this age category were very small, indicating that many car owners do not sell their cars until they reach the 60,000 mileage point and/or that a large portion of the car sales in this age category are intraurban, thus canceling each other out. Given the indirect approach here to monitoring inter-nodal transactions, there is a greater likelihood that only the relative share effect (RSE) of old cars reflects inter-nodal transactions. Accordingly, the RSE was used to isolate simultaneously cities exporting or importing old cars (Figure 3).

In order to examine the filtering-down of cars in a core-periphery context, the boundaries of the functional areas in Israel were laid over the exporters-importers map. The functional division used is based on distance consumption according to an equal opportunity criterion developed and presented in detail by Stern $(1984,1985)$. The approach stems from the unique structure of Israel in which core and periphery cannot be defined according to the comprehensive definitions of Friedmann (1973) but only according to the national space-economy (Vilkansky, 1980). The latter is focused around veteran settlements, both urban and rural, meaning that some of the core areas do not have and urban periphery, as for example, in the case of Jerusalem. Population size therefore may not be an indicator of core status. The resulting spatio-functional division presented in Figure 3, resembles similar divisions, base on commuting flows (Kfir, 1978; Kimchi, et al., 1984), or on internal migration and economic indicators (Shachar and Lipshitz, 1980). The cities included in the analysis limited the study to three functional areas: the metropolitan cores, the metropolitan peripheries and the intermetropolitan areas. No data were available for cities belonging to the national periphery. Despite this limitation, Figure 3 presents a clear pattern of segmentation on a functional area basis. The metropolitan cores and the metropolitan peripheries of Tel Aviv and Haifa are the principal source of old cars for the rest of the country. Jerusalem, however, lacking an urban periphery, imports old cars, as do most of the cities in the inter-metropolitan areas. Two exceptions are evident in the intrametropolitan periphery, the port of Ashdod in the south and veteran city of Nahariya in the north. The former is a main point of entry for new cars and the latter is a well established tourist center; both, however, are small exporters of old cars. Most of the remaining cities in the metropolitan periphery (10 out of 12 ) are developing cities that import old cars. It also should be noted that the below-average importers of old cars (Figure 3) are larger market centers than are the above-average importers.

From these results, the filtering down process cannot be verified without determining the hypothesized direction of the transactions between exporters and importers. This is done in the following section with a linear causal model.

\section{Path Analysis}

As indicated above, car transfer data were not available on an origin-destination basis. In order to examine the direction of inter-nodal transfers, a causal model aimed at explaining the spatial pattern of the RSE of old cars was constructed. The latter, a descriptive device to reflect market demand and supply linkages between local and corresponding national markets (e.g. Williamson, 1980), served as a dependent variable. As argued previously, it was assumed that the external supply, jointly with the local demand for old cars, determines the extent and nature of 


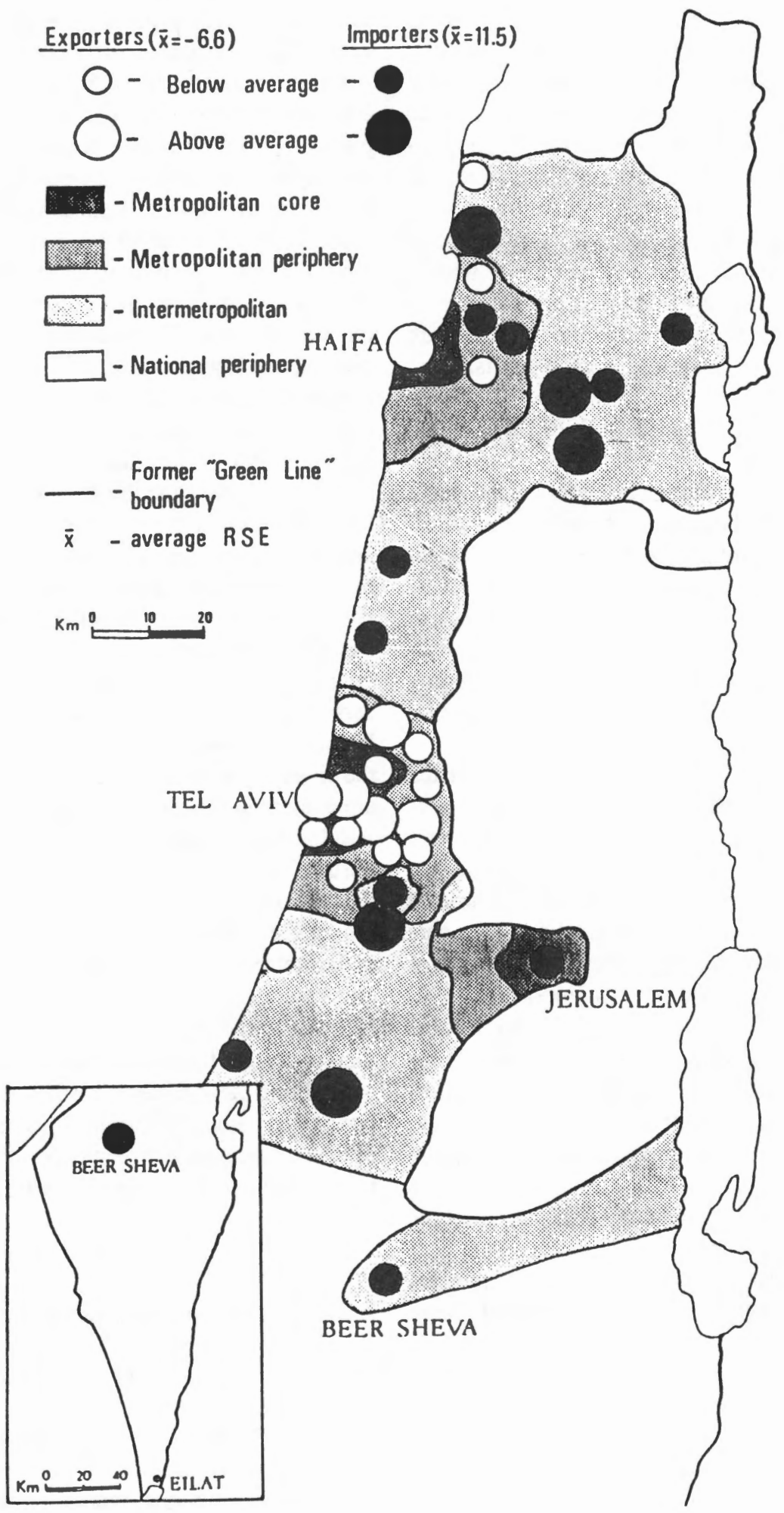

Figure 3. Relative Share Effects (in Percentage) of Old Cars in Israel 
inter-nodal transactions. Thus both could have served as independent variables. However, inter-nodal transactions cannot be measured directly. Therefore, the Heise (1972) Sheaf Coefficient was used in a path analytic scheme to measure internodal transactions (treated as an "induced variable") indirectly. An 'induced variable' is a theoretical construct that cannot, generally and in our case particularly, be measured directly. When a Sheaf Coefficient is selected for computing path coefficients between an induced and a dependent variable, it is derived from the relationship between a set of variable components and the dependent variable. Induced variables thus are to be distinguished from other independent variables because they represent not only a set of variables, but also a set of components of an unmeasured theoretical construct. In the present study, the three functional areas, represented as dummy variables, are the components of the indirectly measured construct, namely, inter-nodal transactions. The Sheaf Coefficient $\left(\mathrm{P}_{\mathrm{s}}\right)$ between the theoretical construct and the RSE of old cars is calculated by the following formula:

$$
P_{S}=\left[\sum_{i} \beta_{i}^{2}+2 \sum_{i} \sum_{j} \beta_{i} \beta_{j} T_{i j}\right]^{1 / 2}
$$

where $\beta_{i}$ is the partial standardized regression coefficient of the $i^{\text {th }}$ independent variable, and $T_{i j}$ is the correlation between the variable-components. The second summation is over all pairs of variables in the functional areas set, and $S$ indicates a coefficient for the induced variable (e.g. internodal transactions).

The estimation of paths from the independent variables to their theoretical construct $\mathrm{S}$, is calculated by the formula:

$$
P_{\text {is }}=\beta_{i} / P_{\text {s }}
$$

The final causal model also includes a demand component for old cars represented by two independent variables, 1) the percentage of carless families, and 2) the percentage of the 20-30 year age group in the population of each city. Auto demand generally is associated positively with income level (e.g. Hocherman and Sternfeld, 1986). However, it has been shown (e.g. Hocherman and Prashker, 1983) that people under 30 and people buying cars for the first time usually have stronger preferences for old cars than other buyers in the same income group. Therefore, the income level, or even the percentage of low income households in each city, would not necessarily reflect only the demand for old cars, but rather a general demand component that may include medium-aged and new cars as well. The two variables included in the model thus are expected to reflect the demand for old cars across all the income groups.

Figure 4 presents the model and its path coefficients. The model explains 85 percent of the total variation in the RSE of old cars across cities, with all regression coefficients being significant at the 0.001 level. Inter-nodal transactions have a higher path coefficient $(0.586)$ than carless families $(0.536)$ or the $20-30$ year age group $(0.477)$. This indicates the relatively role of inter-nodal transactions in explaining the map of the relative share effects of old cars.

The model also provides insight into the role of functional areas of the country in determining inter-nodal transactions. The most important areas are the metropolitan peripheries $\left(P_{2}=0.738\right)$ and the metropolitan cores $\left(P_{1}\right.$ $=0.645$ ) which act as the suppliers of old cars. The positive signs of their path coefficients indicates that movement away from these areas is accompanied by an increase in the number of old cars, and thus by an increase in the average age of all cars in the market. The intermetropolitan areas appear to be the main absorbers of old cars $\left(P_{3}=-0.522\right)$. Running three OLS analyses, each with a different functional area as a reference group, permitted no clear distinction to be made between the metropolitan cores and the metropolitan peripheries with regard to the relative share effect of old cars. The type of change differed among the car markets, however. The dominant factor in a decrease in the relative share effect of old cars in the metropolitan peripheries is a growing export of old cars to other functional areas, while the supply of old cars in the metropolitan cores is, to a larger extent, absorbed locally. This stems from the higher percentage of both carless families and young people in the metropolitan cores.

A clear distinction was found between the inter metropolitan areas and both the metropolitan cores and the metropolitan peripheries that together form the national cores. The difference between the intermetropolitan areas and the metropolitan peripheries, however, is larger. This is due to the importation of relatively more new cars into the metropolitan peripheries than into the metropolitan cores, and hence relatively more old cars are exported from the metropolitan peripheries than from the metropolitan cores. Both, however, are large suppliers of old cars to the intermetropolitan peripheries.

In sum, these findings support the hypothesis of filtering-down as a substantial portion of the old cars found in the intermetropolitan peripheries are cars previously owned by residents of the national core areas.

\section{Regional Impact of the Automobile Filtering Process}

The literature suggests that the spread of household innovations may be neutral spatially (e.g. Gaile, 1979). 


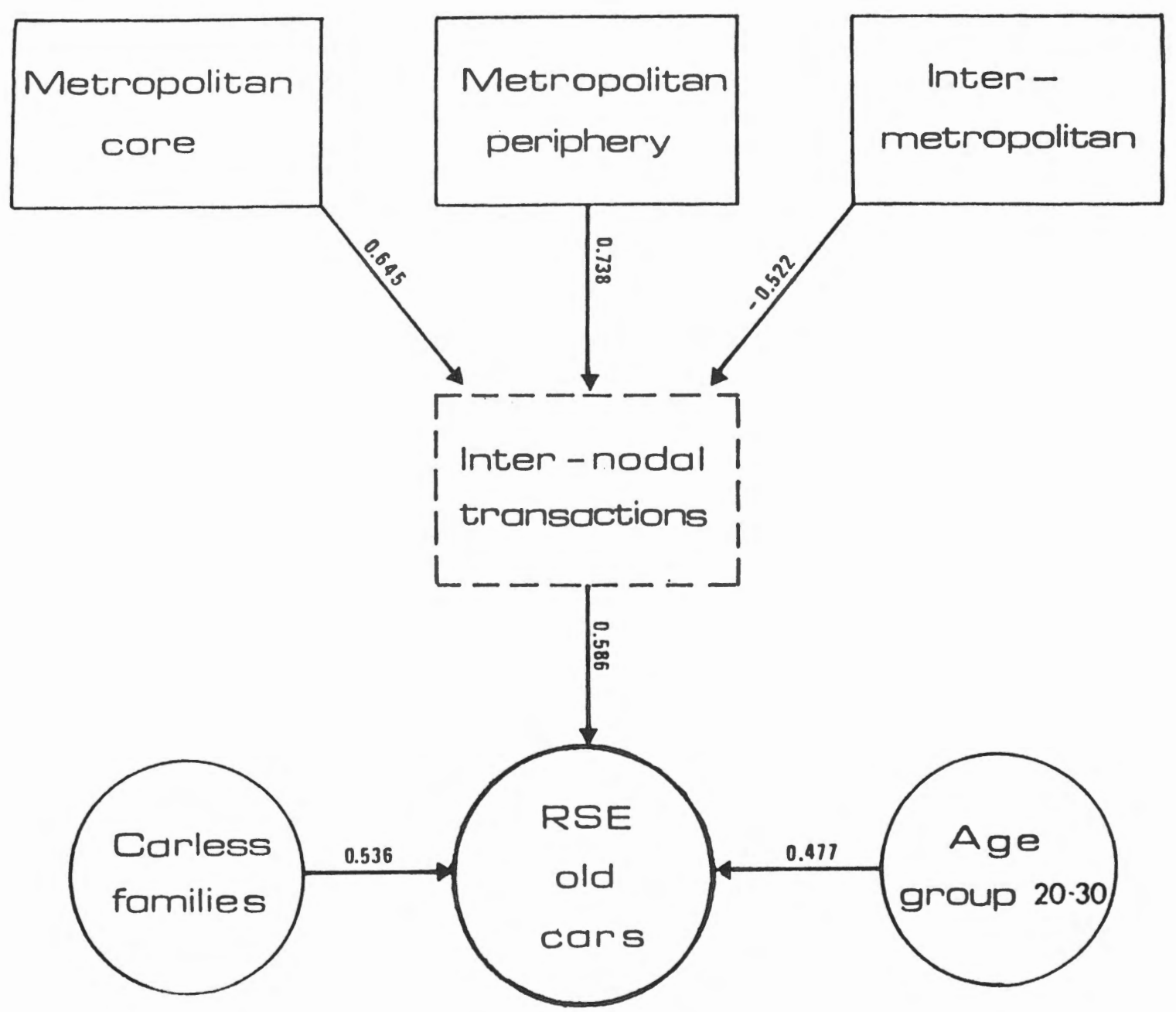

Figure 4. A Causal Path Model of the Relative Share Effects of Old Cars

Being neutral spatially means that the innovation will raise the regional development surface as a whole, but the relative levels of development between the core and the periphery will remain unchanged. Since most of the old cars are bought in core areas, the filtering-down of cars implies an overflow of purchasing power from the periphery to the core. Several studies have supported a similar contention with regard to general wholesaling (Memon, 1974; Lewis and Prescott, 1972; Vance, 1970). Although data are not available on actual car expenditure flows, the additional empirical evidence of Lewis and Prescott (1972) and Hoover (1969) concerning the "trickle up' effect of interregional trade and the hierarchical order of purchasing observed by Nichols (1969), provide further support for the contention that the filtering-down of cars is a core-positive process.
The nature of the process obviously affects the gap between core and periphery with regard to average the age of the private car fleet in both areas. Employing percentage change in the average age of cars between 1981 and 1983, Figure 5 shows the areas with above and below average rates of age reduction. These changes result basically from the consistent shift across all cities toward new cars. It is clear that importers of old cars exhibit low rates of age reduction (94 percent of the cities in this category) and to a slightly lesser extent, exporters of old cars exhibit high rates of age reduction ( 75 percent in this category). Tables 1 and 2 present the results on a core-periphery basis, and reveal a core-positive effect on the spatial car-age balance.

In 1981, the metropolitan cores had the youngest car fleet in Israel and the fleet tended to become older with increasing distance for the cores (Table 1). In 1983, fleet 


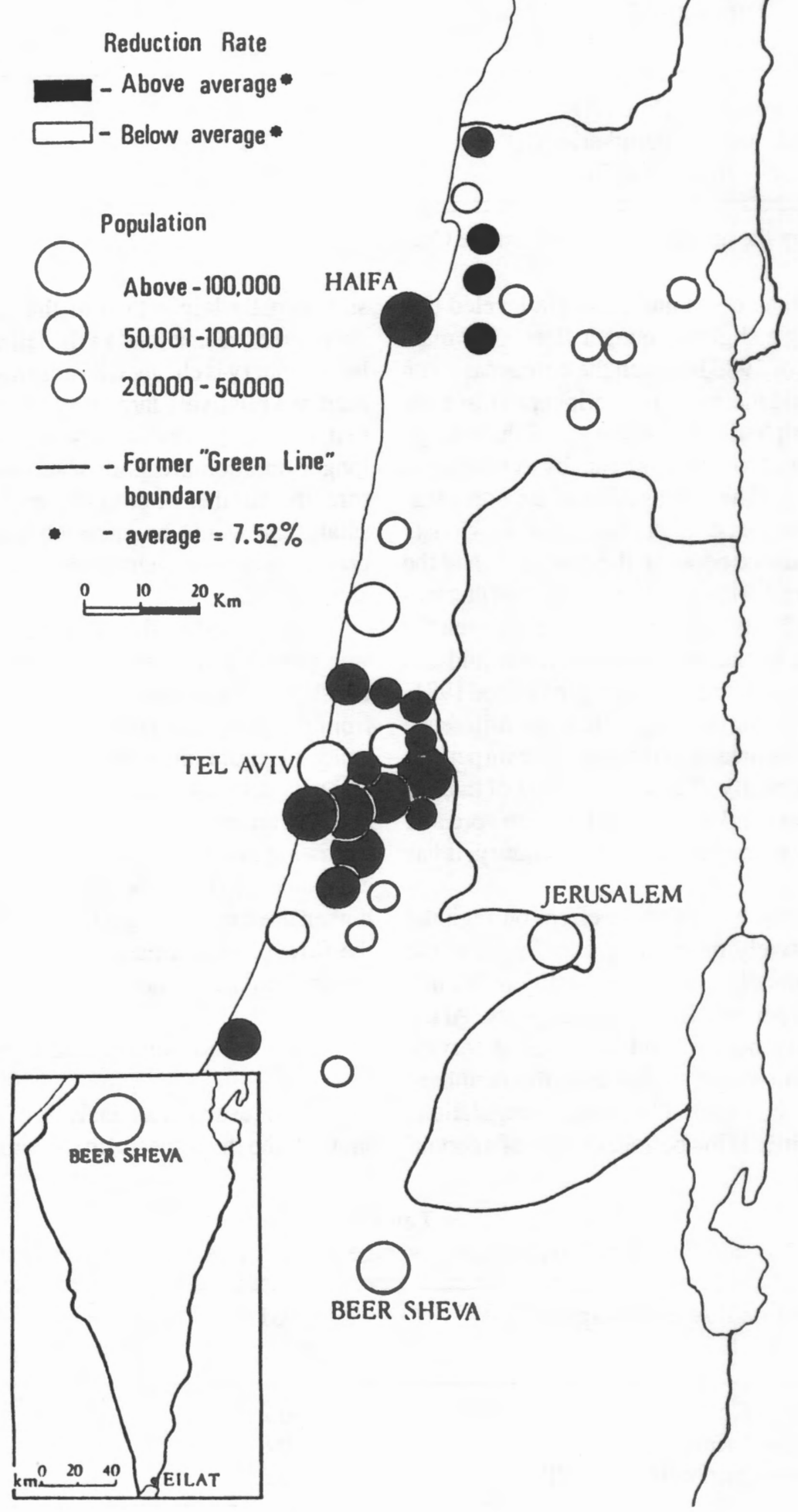

Figure 5. Distribution of Reduction Rates in the Average Age of Private Cars in Israel (1981-1983) 
Table 1

The Average Age of Private Cars in Israel, by functional Areas, 1981 and 1983

\begin{tabular}{lcc}
\hline Functional Areas & $\begin{array}{c}1981 \\
\text { (Years) }\end{array}$ & $\begin{array}{c}1983 \\
\text { (Years) }\end{array}$ \\
\hline Metropolitan Cores (I) & 7.3 & 6.7 \\
Metropolitan Peripheries (II) & 7.5 & 6.6 \\
Inter-Metropolitan (III) & 8.1 & 7.7 \\
\hline \hline
\end{tabular}

Source: computed by the author with data from the Central Bureau of Statistics, 1983.

ages in the metropolitan cores and suburbia leveled out, with the latter having a slightly younger fleet. The main difference at the end of 1983 between the core areas (both metropolitan cores and metropolitan peripheries) and the intermetropolitan peripheries was in the age of the average car. This difference was found significant by a cross-areas $t$ test at the 0.01 level. The average car in the cores was medium-aged, while in the periphery it was old. Obviously the spatial car-age balance between the core areas and the intermetropolitan peripheries was affected by the filteringdown process (Table 2). While the difference between the average age of cars in the metropolitan areas and the metropolitan peripheries decreased during the period 19811983 , with the latter having a younger fleet, the difference between each of the core areas and the metropolitan peripheries increased significantly. Thus, in a period of nationwide growth in the car market, the gap between core and periphery not only has diminished, on the contrary, it has widened.

The widening gap has a further effect on regional inequality. The relatively more older cars found in the periphery, and its generally lower road quality result in a higher need for auto repair services in the periphery. At the same time, the relative number and the level of service provided by auto repair shops are lower in the periphery than in the core (Brosh, 1986). Government regulations force auto repair facilities in the periphery to be of a certain size, usually larger than in the core, due to the general shortage of vacant land in the latter. Although the land in the periphery is cheaper, an auto repair facility there would require a relatively large investment. Moreover, periodic maintenance services of new cars are more profitable than longer-duration breakdown services for old cars. Therefore, the number of auto repair shops in the periphery is small than would be expected and the filtering-down of private cars consequently increases regional inequality in auto services.

Empirical evidence of the outcome of this process was provided recently by Brosh (1986). According to Brosh, two phenomena are likely to emerge, both negative from the periphery point of view. The first is the emergence of pirate, uncontrolled backyard auto repair shops that may decrease road safety through provision of unreliable and unauthorized mechanical services. The second is a growing trend, especially among large public and private companies, to have their vehicles serviced in authorized, higher level repair shops in the core area. Consequently, the flow of expenditures from the periphery to the core would increase further.

\section{Summary and Conclusion}

The results of an analysis of the car market in Israel support the hypothesis that a core-periphery filtering-

Table 2

Difference Between Functional Areas in the Average Age of Private Cars in Israel, 1981 and 1983

\begin{tabular}{crcc}
\hline \hline Functional Areas Compared* & $\begin{array}{c}1981 \\
\text { (Years) }\end{array}$ & $\begin{array}{c}1983 \\
\text { (Years) }\end{array}$ \\
\hline Within Cores & I-II & -0.2 & 0.1 \\
Cores-Peripheries & I-III & -0.8 & -1.0 \\
Cores-Peripheries & II-III & -0.6 & -1.1 \\
\hline \hline
\end{tabular}

Notations, see Table 1

Source: see Table 1 
down process characterizes the spread of private cars. It was found that the intermetropolitan areas are the main importers of old cars while the metropolitan peripheries are the main exporters. Thus the average age of cars outside the metropolitan areas is higher than in the metropolitan areas. Within the metropolitan areas, the younger car fleet is found in the metropolitan peripheries.

The study covered a period of a consistent shift throughout the country away from old cars toward new cars. The results indicate that even in a period of growth in the national car market, regional inequality increased because of the core-positive effect of the filtering-down process. It was concluded, therefore, that a core-periphery spread of first-order goods should not be expected. Instead, the periphery always would be expected to have a relatively larger share of secondary goods than the core. In the case investigated here, this was demonstrated by the filtering-down process by which the periphery absorbs the "junk" cars of the core.

\section{References}

Ajo, R. "An Analysis of Automobile Frequencies in a Human Geographic Continuum," Lund Studies in Geography B, 15 (1955) 3-16.

Berry, B.J.L. "Hierarchical Diffusion: The Basis of Developmental Filtering and Spread in a System of Growth Centers," in Hansen, N.M. (ed.), Growth Centers in Regional Economic Development, New York: The Free Press, 1972.

Boddy, M.J., and F. Gray. "Filtering Theory, Housing Policy and the Legitimation of Inequality"., Policy and Politics, 7 (1979) 39-54.

Brosh, D. The Spatial Distribution of Automobile Service Facilities in Israel, Beer Sheva: Department of Geography, Ben-Gurion University of the Negev, (in Hebrew), 1986.

Brown, A.L. Innovation Diffusion - A New Perspective, New York: Methuen, 1981.

Carpenter, S.M., M.I. Clarke, and M.C. Dix. Household Activity. Trip Generation and Car Use: An Overview, and Implications for Forecasting, Oxford University: Transport Studies Unit, 142/CP, 1980.

Central Bureau of Statistics. Motor Vehicles, Special Series (1967-1983), Jerusalem.

Central Bureau of Statistics. Transportation Quarterly, 4, Jerusalem, 1983.

Cohen, A. "Market Dependency, Accessibility, and Urban Attractivity," City and Region, 3 (1976) 69-73.

Friedmann, J. Urbanization. Planning and National Development. Beverly Hills: Sage Publications, 1973.

Gaile, L. Gary. "Spatial Models of Spread-Backwash Processes," Geographical Analysis, 11(3) (1979) 273-288.

Gordon, R.I. "Economic Explanations of Spatial Variation in
Distance Deterrence," Environment and Planning A, 17 (1985) 59-72.

Grigsby, W. Urban Housing Markets, Philadelphia: University of Pennsylvania Press, 1963.

Heise, D.R. "Employing Nominal Variables, Induced Variables, and Block Variables in Path Analysis," Sociological Methods and Research, 1 (1972) 147-173.

Hensher, A.D. "Model Specification for a Dynamic Discrete Continuous Choice Automobile Demand System," in Golledge, G.R., and Timmermans, H. (eds.), Behavioural Modelling in Geography and Planning, Kent: Croom Helm, $1988,451-476$.

Hensher, A.D., and V. Le Plastrier "Towards a Dynamic Discrete Choice Model of Household Automobile Fleet Size and Composition," Transportation Research B, 19 (1985) 481. 498.

Hirschmann, A.O. "Interregional and International Transmission of Economic Growth," in McKee, D.H., Dean, D.R., and Leahy, H.W. (eds.), Regional Economics: Theory and Practice, New York: The Free Press, 1970, 105-120.

Hocherman, I., and J. Prashker. Factors Affecting Car Ownership in Israel, Research Report No. 83-20, Haifa: Technion - Israel Institute of Technology, 1983.

Hocherman, I., N.J. Prashker, and M. Ben-Akiva. "Estimation and Use of Dynamic Transaction Models of Automobile Ownership," Transportation Research Record, No. 944(1984) 134-141.

Hocherman, I., N.J. Prashker, and M. Ben-Akiva. "The Transaction Cost Approach to Modeling the Demand for Automobiles," Journal of Adv anced Transportation, 21 (1987) 173 193.

Höcherman, I., and Z. Stemfeld. Analysis of Car Ownership Data from the 1983 Population Census, Road Safety Center, Research Report No. 96-103, Haifa: Technion, 1986.

Hoover, E.M. "Some Old and New Issues in Regional Development," in Robinson, E.A.G. (ed.) Backward Areas in Advanced Countries, London: Macmillan, 1969.

Hopkin, M.I. "The Role of an Understanding of Social Factors in Forecasting Car Ownership," in Carpenter, S., and Jones, P. (eds.) Recent Advances in Travel Demand Analysis, Aldershot: Gower, 1983, 93-114.

Kfir, G. Similarity in Commuting Patterns: Analysis of Spatial Variations in Commuting Patterns in the Tel-Aviv Metropolitan Area, Tel Aviv: The Israel Institute of Transportation Planning and Research, 1978.

Kimchi, Y., S. Reichman, Y. Shveid. Delineating the Metropolitan Area of Jerusalem, Jerusalem: The Jerusalem Institute for Israel Research, Study Report 6, 1984.

Kirkland, J.S. "Housing Filtration in Kingston 1953-1968," Unpublished M.A. Thesis, Department of Geography, Queen's University, Kingston, 1969.

Lansing, J.B., and G. Hendricks. Automobile Ownership and 
Residential Density Ann Arbor: Institute for Social Research, University of Michigan, 1967.

Lave, A.C., and J. Bradley. "Market Share of Imported Cars: A Model of Geographic and Demographic Determinants," Transportation Research A, 14 (1980) 379-387.

Lave, A.C., and K. Train. "A Behavioral Disaggregate Model of Auto Type Choice," Transportation Research A, 13 (1979) 1-9.

Leven, C.L., et al. Neighborhood Change: Lesson in the Dynamics of Urban Decay, New York: Praeger, 1976.

Lewis, C., and J.R. Prescott. "Urban-Regional Development and Growth Centres: An Econometric Study," Journal of Regional Science, 12 (1972) 57-70.

Manski, C.F., and L. Sherman. "An Empirical Analysis of Household Choice Among Motor Vehicles." Transportation Research, 14 (1980) 349-366.

Meir, A. "Innovation Diffusion and Regional Development: The Spatial Diffusion of Automobiles in Ohio," Regional Studies, 15 (1981) 111-122.

Memon, P.A. Mercantile Intermediaries in a Colonial Spatial System: Wholesaling in Kenya, Unpublished Ph. D. Dissertation, University of Western Ontario, London, Ont., 1974.

Nichols, V. "Growth Poles: An Evaluation of their Propulsive Effect," Environment and Planning A. 1 (1969) 193-208.

Pashingian, B.P. The Distribution of Automobiles - An Economic Analysis of the Franchise System, New Jersey: Prentice Hall Inc., 1961.

Riddel, J.B. The Spatial Dynamics of Modernization in Sierra Leone, Evanston: Northwestern University Press, 1970.
Shacar, A., and G. Lipshitz. "The Spatial Organization of InterRegional Migration in Israel," Studies in the Geography of Israel, 11 (1980) 153-178.

Shacar, A., and G. Lipshitz. "Regional Inequalities in Israel," Environment and Planning A. 13 (1981) 463-473.

Smith, M.D. Geographical Perspectives on Inequality, New York: Bames \& Noble Books, 1979.

Stem, E. "Delineating Regions for Transit Assistance Allocation," Applied Geography, 14 (1984) 267-281.

Stem, E. "The Functional Spaces of Israel According to the Equal Opportunity Criteria," Studies in Geography, 13 (1985) 185205.

Tanner, C.J. Car Ownership Trends and Forecasts, Crowthome: Laboratory Report 799, Transport and Road Research Laboratory, 1977.

Thompson, W.R. "Internal and External Factors in the Development of Urban Economics," in Perloff, H., and Wingo, R. (eds.) Issues in Urban Economics, Washington, D.C.: Resources for the Future, Inc., 1968, 43-80.

Vance, E.J., Jr. The Merchant's World: The Geography of Wholesaling, New Jersey: Prentice-Hall, Inc., 1970.

Vilkansky, R. Core and Periphery in the Development of Israel, Unpublished Ph. D. thesis, The Technion, Haifa, 1980.

Williams, W.S. "Internal Colonialism, Core-Periphery Contrasts and Devolution: An Integrative Comment," Area, 9 (1977) 272-278.

Williamson, B.R. "Forecasting Regional Exports - New Tests of Shift-Share Technique, Growth and Change, 11 (1980) 19 25. 